MATEC Web of Conferences 17, 01018 (2014)

DOI: $10.1051 /$ matecconf/ 20141701018

(C) Owned by the authors, published by EDP Sciences, 2014

\title{
Investigation of Mechanical Properties of Coconut Fiber as a Concrete Admixture
}

\author{
M.S. Ramli ${ }^{1}$, N.F. Abas ${ }^{2, a}$, M.A. Othuman Mydin ${ }^{3}$ \\ ${ }^{1,2,3}$ School of Housing, Building and Planning, Universiti Sains Malaysia, 11800, Penang, Malaysia
}

\begin{abstract}
The high cost of conventional construction materials is the dominating factor affecting housing systems worldwide. Because of this, further research into alternative materials in construction is required. The purpose of this study is to experimentally investigate the physical characteristics and mechanical properties of concrete produced using shredded coconut fibre composites. The following percentage amounts of fibre were tested: $0 \%$ (control), $0.6 \%$, and $1.8 \%$. The coconut fibres were cut to a certain length according to previous studies which suggested that the most ideal length is around 30 $60 \mathrm{~mm}$. The test results showed that the compressive strength of concrete decreased as the percentage of total fibre in the concrete mix increased. The experimental results also showed that coconut fibre concrete performed satisfactorily in terms of crack growth in comparison to that of conventional concrete. Finally, it was concluded that the use of coconut fibres has great potential in the production of lightweight concrete or normal concrete for use in the construction of concrete structures. As coconut fibre is a natural material that is easily available and cheap, it is a particularly good, low-cost alternative. Therefore, this material has the potential to overcome the problem of escalating costs in the industry.
\end{abstract}

\section{Introduction}

There is currently a great deal of interest in developing technology towards the use of natural fibre materials in cement composites. Natural fibres are present in relatively large quantities all over the world and natural vegetable fibres are produced in most developing countries. Such natural fibres have been used to strengthen non-organic materials for thousands of years. Examples include straw for brick, mud in poles, and plaster with bamboo [1]. In this century, fibres such as those from coconut, bamboo, wood cellulose, wool or chips, bark, leaves, seeds and fruits have been used in sand-based cement products. Fibres can be divided into two categories: natural and man-made. The advantages of using natural fibres are that the materials are readily available, inexpensive and environmentally friendly. The existence of these natural materials can be renewed, so reliance on limited resources or resources that are not environmentally friendly will be reduced [2].

Extensive research and development in the understanding and application of fibre concrete materials is still taking place all over the world. Advances include, amongst other things, the development of new, stronger fibres, better fibre reinforced composites and new substitutes [3]. This study reports the results of an investigation carried out on the utilisation of chopped coconut fibre

${ }^{a}$ Corresponding author : nfaisal@usm.my

This is an Open Access article distributed under the terms of the Creative Commons Attribution License 4.0, which permits unrestricted use, distribution, and reproduction in any medium, provided the original work is properly cited. 
composites in concrete as admixtures. The physical and mechanical properties of plain concrete were also compared with coconut fibre composite concretes. The main objective is to encourage the use of these supposed "waste products" as construction materials.

\section{Materials}

There are three basic processes in the manufacture of concrete blocks which are mixing, moulding, and curing. The experiment was set up to analyse data on the manufacturing of concrete with concrete waste as a cement replacement for making concrete blocks [4].

\subsection{Cement}

Portland cement is a hydraulic cement produced from sublimate clinker which is mainly composed of silicate, calcium silicate hydrolysis nature added to the material arrange tie (generally gypsum). Cement works by gluing the particles that make up an aggregate compact mass and also by filling the air cavities between the aggregate grains [5].

\subsection{Fine Aggregate}

An aggregate in the form of sand is the result of the natural disintegration of rock or from manufactured sand produced by crushing devices. A fine aggregate consists of components that are both sharp and hard. Such components should be permanent, meaning they cannot be broken or destroyed by the influence of weather like sun and rain [6].

\subsection{Coarse Aggregate}

A coarse aggregate is made of large grains that are more than $5 \mathrm{~mm}$ in diameter. The requirements of coarse aggregate demand that it also be permanent, meaning it will suffer no breaks or destruction due to the influences of weather, such as sun and rain [7].

\subsection{Admixture}

In this study, coconut fibres were used as an added material in the concrete mixture. The fibres were cut to lengths of around $30-60 \mathrm{~mm}$ and a certain amount was combined with the concrete mixture. Concrete prisms and cubes were tested on $3,7,14$ and 28 days after formation.

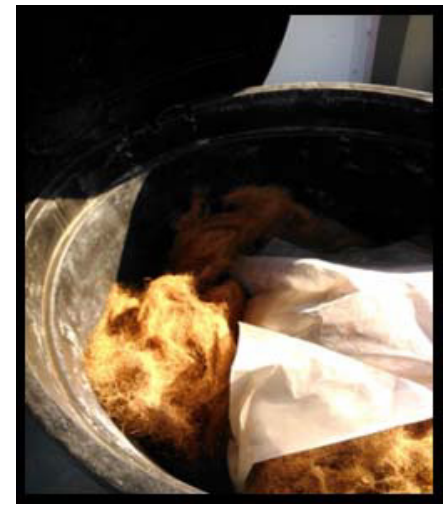

Figure 1.Coconut Fibres

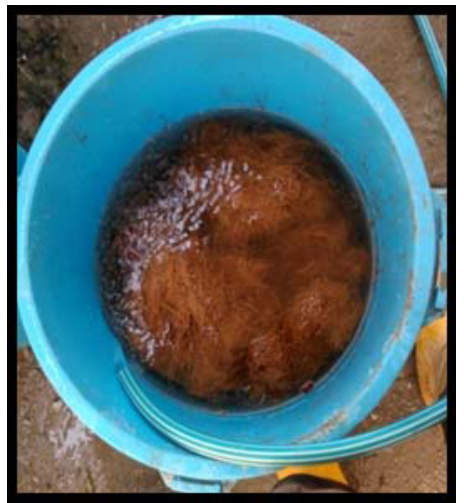

Figure 2. Fibres Being Washed

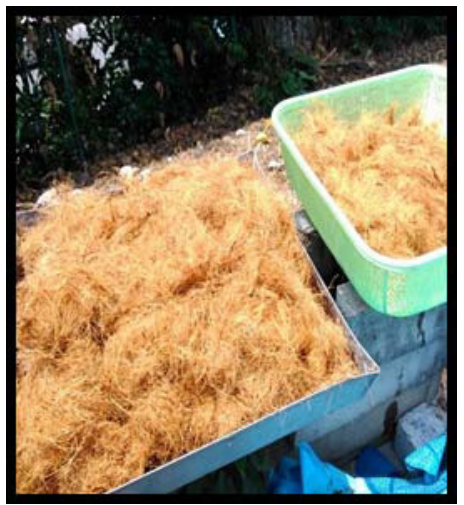

Figure 3. Fibres Being Dried 
Table 1. Table of Material Contents

\begin{tabular}{|c|c|c|c|c|c|c|}
\hline Concrete mix & $\begin{array}{c}\text { Cement } \\
\left(\mathrm{kg} / \mathrm{m}^{3}\right)\end{array}$ & $\begin{array}{c}\text { Fine } \\
\text { aggregates } \\
\left(\mathrm{kg} / \mathrm{m}^{3}\right)\end{array}$ & $\begin{array}{c}\text { Course } \\
\text { aggregates } \\
\left(\mathrm{kg} / \mathrm{m}^{3}\right)\end{array}$ & $\begin{array}{c}\text { Water } \\
\left(\mathrm{kg} / \mathrm{m}^{3}\right)\end{array}$ & $\begin{array}{c}\text { Coconut } \\
\text { Fibres } \\
(\%)\end{array}$ & $\begin{array}{c}\text { Coconut } \\
\text { Fibres } \\
\left(\mathrm{kg} / \mathrm{m}^{3}\right)\end{array}$ \\
\hline C & 31.05 & 70.63 & 79.63 & 17.39 & 0 & 0 \\
\hline CF1 & 31.05 & 70.63 & 79.63 & 17.39 & 0.6 & 0.5 \\
\hline CF2 & 31.05 & 70.63 & 79.63 & 17.39 & 1.8 & 0.75 \\
\hline
\end{tabular}

\subsection{Water}

Water was used as a mixing agent for the concrete and admixtures to facilitate the experimental setup. It was purely organic and did not contain salts or acids that could damage the concrete.

\section{Experimental Setup}

\subsection{Manufacturing Process}

Materials used to produce the concrete were measured to specific weights and ground in a concrete mixer. Materials such as coarse aggregate, fine aggregate, cement, water and coconut fibres were gradually inserted into the machine. This method was intended to ensure that the concrete had a perfect consistency. Further concrete was then placed in the prepared moulds (prism and cube) while the concrete compression was done on the table vibrator to ensure that the moulded concrete was compressed properly. Concrete was left to harden for 24 hours in the mould before being released the following day. For the purpose of curing the concrete, the prisms and cubes were placed in water. They were then removed from the immersion vat and tested for various stages at days 3, 7, 14 and 28 .

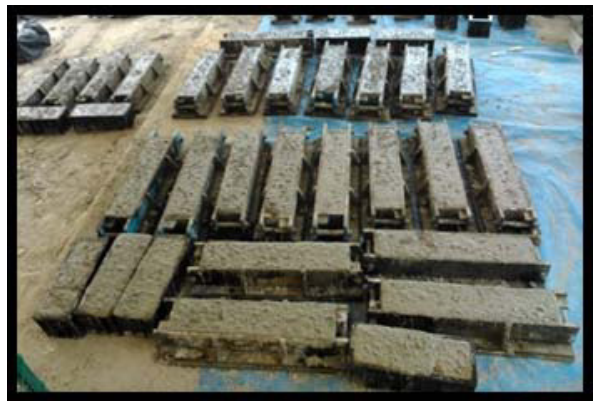

Figure 4 . Concrete being placed in mould

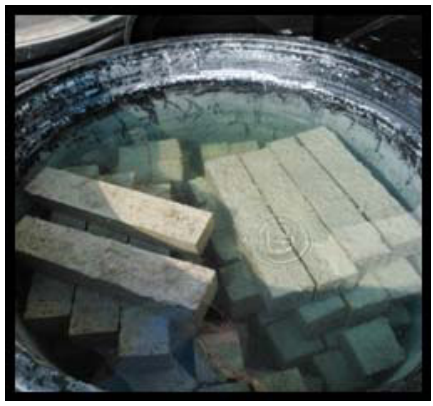

Figure 5. Prism and Cube in water for curing

\subsection{Testing}

After the concrete had hardened into prisms and cubes, it was removed from the bath and tested on certain days. Experiments were then preformed on the prisms and cubes to test for strength. Compressive strength was assessed for the cubes, while the prisms were testing for bendability. Two of these tests were to obtain data on the strength of concrete mixed with specific proportions of coconut fibre. Other tests performed on the concrete samples included pulse velocity tests, density tests and water absorption tests. For comprehensive testing, each test was repeated after the concrete had soaked over the course of $3,7,14$, and 28 days. 


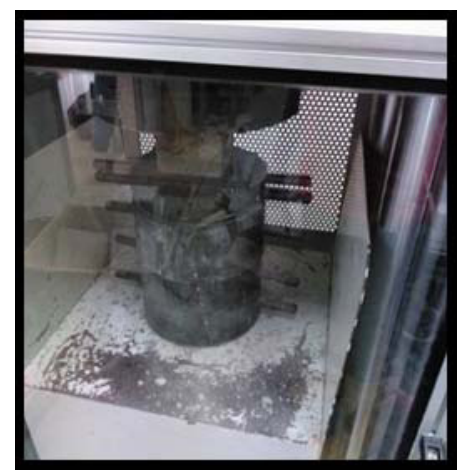

Figure 6. Compression Test

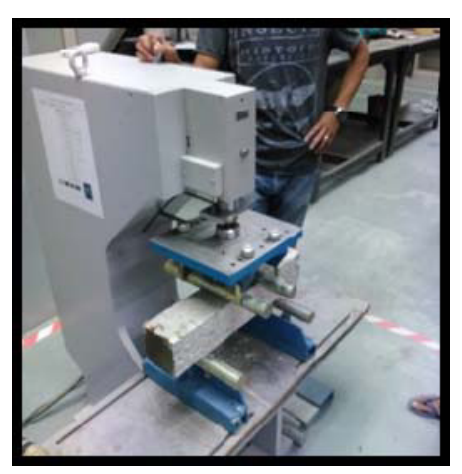

Figure 7. Flexural Test

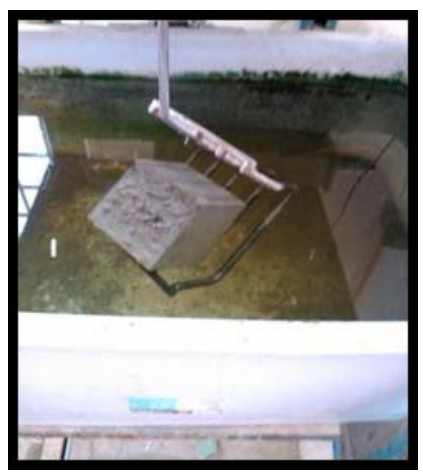

Figure 8. Density Test

\section{Results and Discussion}

\subsection{Compressive Strength Test}

According to the graph in Figure 9, it was found that the compressive strength of the tested concretes increased from the age of 3 days to 28 days. The concretes demonstrated substantial increases in compressive strength at the age of 7 days, which then continued to increase to the highest strength that could be produced at 28 days of $29.8 \mathrm{MPa}$ for the $0.6 \%$ mix and $27.8 \mathrm{MPa}$ for the $1.8 \%$ coconut fibre mix. Through the collected data it can be seen that the compressive strength of the control had a significantly higher reading than both of the fibre-mix concretes. Though the compressive strength of the fibre mixes increased for each age, there was little improvement compared to the control concrete. By reviewing the data, it can be concluded that the concrete containing $0.6 \%$ coconut fibre was stronger than the concrete containing $1.8 \%$ fibre.

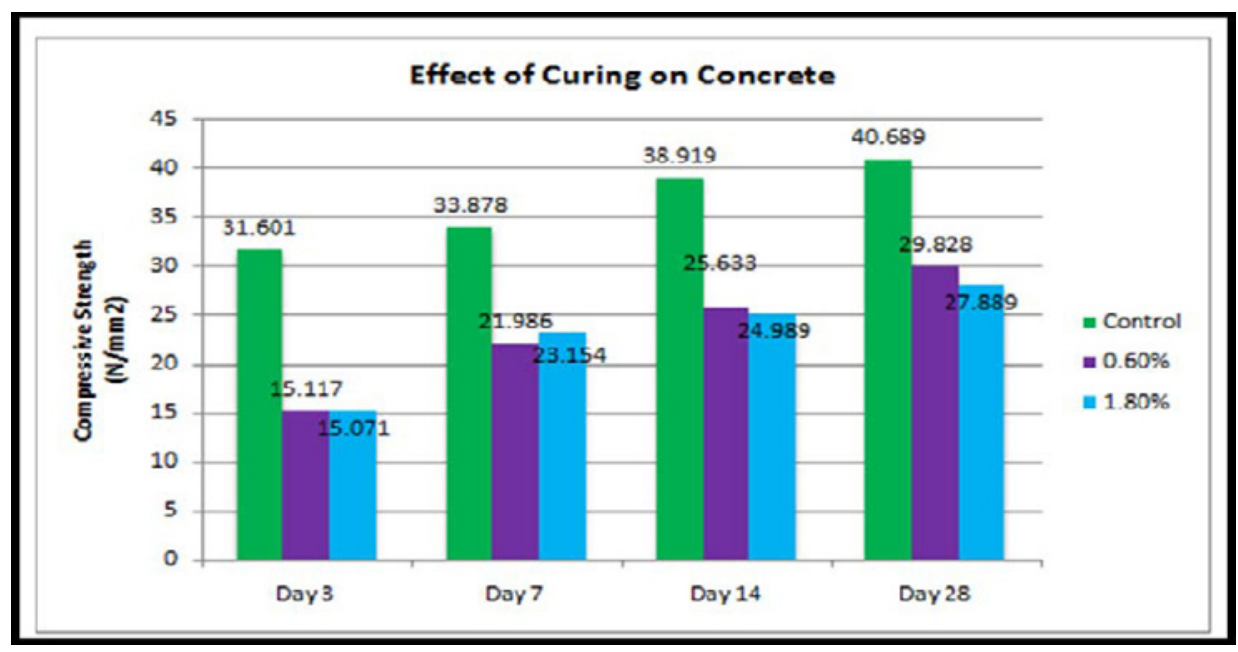

Figure 9. Changes in Compression Strength of Concrete by Different Durations of Curing.

\subsection{Flexural Strength Test}

From the results that were obtained, it was found that the flexural strength of the control concrete increased in direct proportion to an increase in the concrete's age. Increases occurred from the ages of $3,7,14$, and 28 days. The highest increase in flexural strength occurred following $33.8 \mathrm{MPa}$ and 
$38.9 \mathrm{MPa}$ at days 3 and 7 , respectively, with a jump to $5041 \mathrm{MPa}$ at 14 days. Meanwhile, the concretes containing $0.6 \%$ and $1.8 \%$ fibre both demonstrated increases in flexural strength. The highest readings were achieved at 28 days with a value of $29.8 \mathrm{MPa}$ for the $0.6 \%$ fibre concrete and $27.8 \mathrm{MPa}$ for the $1.8 \%$ fibre concrete. A comparison of flexural strengths showed that the control concrete was stronger than both ratios of the fibre-mix concretes.

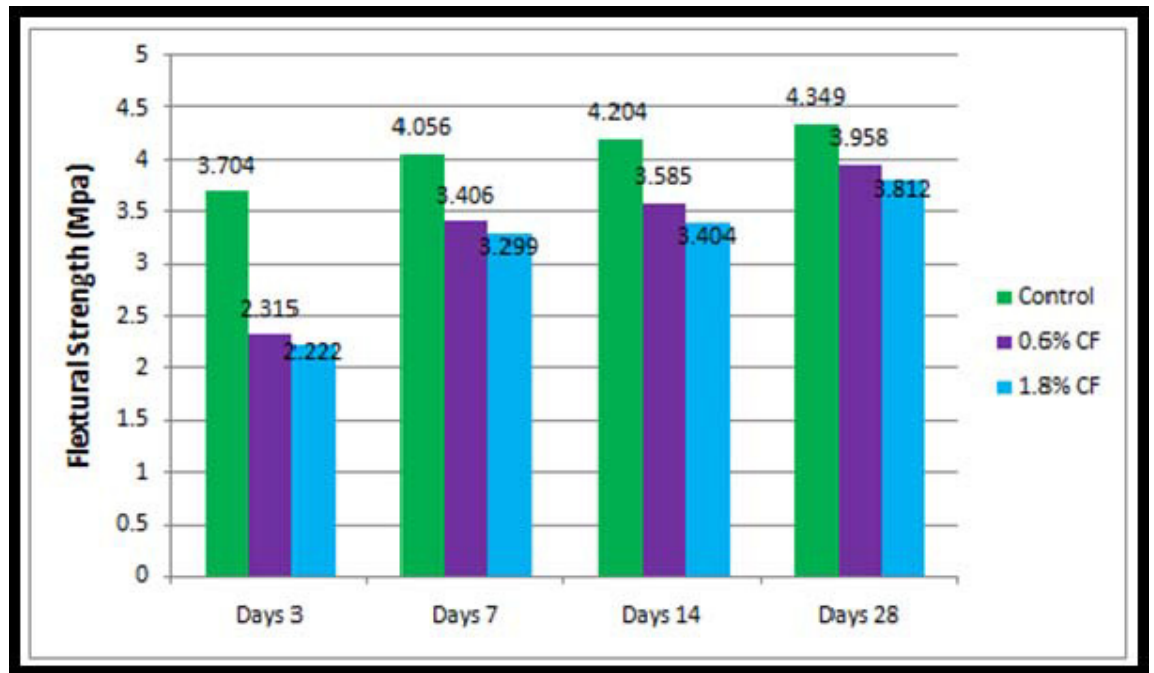

Figure 10. Comparison of Flexural Strength for the Control, $0.6 \%$, and $1.8 \%$ Fiber Mixes Against Age

\subsection{Water Absorption Test}

Table shows the rate of water absorption for the control concrete, $0.6 \%$, and $1.8 \%$ fibre mixes. From the data obtained, the rate of diffusion of water for the $1.6 \%$ and $1.8 \%$ fibre mixes decreased starting from the age of 3 days (6.49\% and $6.24 \%$, respectively) to 28 days ( $4.41 \%$ and $4.09 \%$, respectively). As for the control, the readings also showed a decline from the age of 3 days $(5.55 \%)$ to 28 days $(3.27 \%)$.

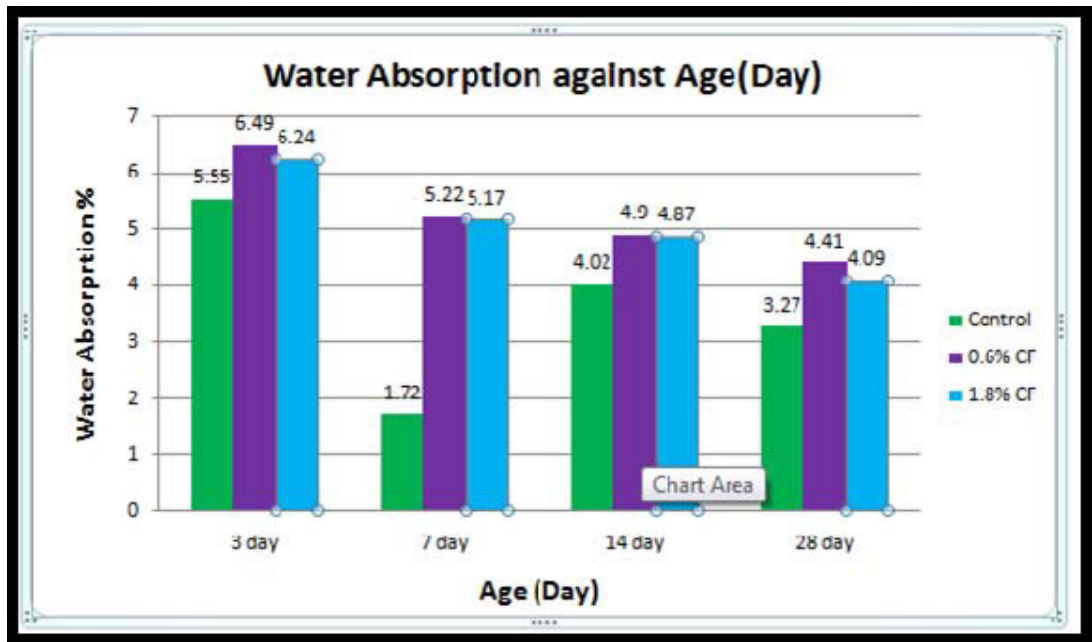

Figure 11. Comparison of Water Absorption Rates for the Control, $0.6 \% \& 1.8 \%$ Fiber Mixes by Age 


\section{Conclusion}

In this study, the results of experimental tests studying the physical and mechanical properties of concrete with different percentages of coconut fibre admixture were presented. Based on the experimental results and observations, the following conclusions have been made:

- In all cases, the compressive strength decreased as the percentage volume of coconut fibre in the concrete mix increased.

- From the data, it can be concluded that the concrete mixed with fibres had less strength than normal concrete, but its strength still remains relevant.

- Natural fibres are readily available, inexpensive and environmentally friendly.

- Though concrete made from a coconut fibre admixture may not be used for main building structures, it still has potential for use in other structures such as non-loadbearing walls, floors and others.

Overall, since coconut fibre is a cost effective and easily obtainable resource with notable strength when added to concrete, its benefits should not be overlooked. It shows great potential for use in conventional concrete as a form of lightweight, structural concrete.

\section{References}

1. SaandeepaniVajje, Dr.N.R.Krishnamurthy (2013). Study On Addition Of The Natural Fibers Into Concrete,International Journal Of Scientific \& Technology, Research Volume 2, Issue 11, November 2013.

2. Abdul Karim, I.A (2012). Study The Effect of Coconut Waste on Concrete Structure Component,UniversitiTeknikal Malaysia Melaka, June 2012.

3. Yalley, P. P. and Kwan, A.S K. (2005). Use Of Coconut Fibres As An Enhancement Of Concrete,School of Engineering, Takoradi Polytechnic, Takoradi, Ghana. School of Engineering, Cardiff University, Cardiff,UK, 2005.

4. Gheorghe Asachi. (2008). Properties Of Fiber Reinforced Polymer Concretecoir Fibre.UniversitateaTehnic ${ }^{\swarrow}$.

5. ElieAwwad, MounirMabsout, Bilal Hamad and HelmiKhatib (2010). Preliminary Studies On The Use Of Natural Fibers In Sustainable Concrete,Civil and Environmental Engineering, American University of Beirut, Lebanese Science Journal, Vol. 12, No. 1, 2011.

6. M.Sivaraja, (2010). Application of Coir Fibres as Concrete Composites for Disaster prone Structures,Kongu Engineering College, Perundurai, March 2010.

7. Amezugbe, F.A. (2013). The Performance Of Natural And Synthetic Fibers In Low Strength,University Of Florida , May 2013. 